\title{
Improved immediate breast reconstruction as a result of oncoplastic multidisciplinary meeting
}

This article was published in the following Dove Press journal:

Breast Cancer - Targets and Therapy

28 April 2017

Number of times this article has been viewed

\author{
Mohsen M El Gammal' \\ Maria Lim' \\ Rajan Uppal ${ }^{2}$ \\ Richard Sainsbury' \\ 'Department of Breast Surgery, \\ Parapet Breast Centre, Frimley \\ Health Foundation Trust, Windsor, \\ ${ }^{2}$ Department of Plastic and \\ Reconstructive Surgery, Wexham \\ and Heatherwood Hospital, Frimley \\ Health Foundation Trust, Slough, UK
}

Correspondence: Mohsen M EL Gammal Department of Breast Surgery, Parapet Breast Centre, Frimley Health Foundation Trust, Windsor SL4 3DP, UK

Tel +44 1753636706

Fax +44 1753636298

Email Mohsen.elgammal@fhft.nhs.uk
Introduction: The National Institute for Health and Clinical Excellence guidelines recommend that breast reconstruction should be available to all women undergoing mastectomy and discussed at the initial surgical consultation (2002, and updated 2009). The National Mastectomy and Breast Reconstruction Audit (2009) showed that 21\% of mastectomy patients underwent immediate breast reconstruction (IBR) and $11 \%$ had delayed breast reconstruction (DBR). Breast reconstruction has been shown to have a positive effect on quality of life postmastectomy. This retrospective study investigated the impact of the introduction of a dedicated oncoplastic multidisciplinary meeting (OP MDM) on our unit's breast reconstruction rate.

Patients and methods: A retrospective analysis of 229 women who underwent mastectomy, of whom 81 (35\%) underwent breast reconstruction between April 2014 and March 2016. Data were analyzed before and after introduction of OP MDM in April 2015. Data on patient age, type of surgery (mastectomy only, mastectomy and reconstruction), timing of reconstruction (IBR, DBR), and type of reconstruction (implant, autologous) were collected.

Results: Between April 2015 and March 2016, following establishment of OP multidisciplinary team in April 2015, of the 120 patients who had mastectomy, 50 (42\%) underwent breast reconstruction with $78 \%$ (39/50) choosing IBR (56\% implant reconstruction and $22 \%$ autologous). Compared to the period between April 2014 and March 2015 preceding the OP MDM, of 109 patients who underwent mastectomy, only 31 (28\%) had breast reconstruction with $64 \%(20 / 31)$ choosing IBR (45\% implant reconstruction and 19\% autologous). The rate of DBR was lower, $22 \%$ (11/50), following OP MDM compared to 35\% (11/31) before OP MDM.

Conclusion: There has been an increased uptake of breast reconstruction surgery from $28 \%$ to $42 \%$. The biggest impact was on those opting for the immediate type reconstruction option (78\%). The OP MDM has significantly contributed to this increased rate of reconstruction.

Keywords: breast cancer, delayed reconstruction, uptake rate, mastectomy

\section{Introduction}

The National Institute for Health and Clinical Excellence guidelines recommend that reconstruction should be available to all women undergoing mastectomy and should be discussed at the initial surgical consultation. ${ }^{1}$ In the UK, the National Mastectomy and Breast Reconstruction Audit (NMBRA) showed that in 2009, 21\% of mastectomy patients underwent immediate reconstruction with an additional 11\% having delayed reconstruction. ${ }^{2}$ Breast reconstruction has been shown to have a positive effect on quality of life postmastectomy. ${ }^{3}$ Breast reconstruction rates vary widely across the UK, but overall remain low with only $16.9 \%$ of women undergoing 
immediate or delayed reconstruction (range $4.9 \%-81.2 \%$, median $23.3 \%$ ). ${ }^{4}$ Rates of reconstruction could be increased with early discussion of the options when mastectomy is chosen or required. ${ }^{4}$ Multidisciplinary team (MDT) working is considered as the "gold standard" in terms of cancer patient management. MDTs have also been shown to deliver a number of improvements in the quality of care and patient outcomes. ${ }^{5-7}$ The oncoplastic multidisciplinary meeting (OP MDM) should be the central component of the oncoplastic services for National Health Service (NHS) and private patients. It should provide balanced information and advice about reconstruction, as well as the timing and types of appropriate procedures. ${ }^{8}$ All cases for reconstruction should be discussed by the members of the OP MDM team during a weekly meeting. This is not currently practiced by some centers offering reconstruction although their symptomatic and screen-detected cancers are discussed at the standard breast MDT.

The aim of this study is to assess the impact of the introduction of a dedicated OP MDT on the breast reconstruction rate in a single unit.

\section{Patients and methods}

A retrospective analysis of 819 patients diagnosed with breast cancer between April 2014 and March 2016 in our Unit. Two hundred twenty-nine women had mastectomy (27.9\%), of whom 81 (35\%) underwent reconstruction. Data analysis was made before and after introduction of OP MDM in April 2015. Electronic data were collected including surgical operating notes, clinical letters, and breast care nurses (BCNs) records. Data from Somerset Cancer Registry (SCR) of MDT and OP MDM decisions including data records of patient age, type of surgery (mastectomy only, mastectomy with reconstruction), timing of reconstruction (immediate breast reconstruction [IBR] or delayed breast reconstruction [DBR]), and type of reconstruction (implant, autologous) were collected. Fisher's exact test was used to compare the groups. Approval of Wexham and Heatherwood Hospitals Clinical Audit Lead and committee was granted before conducting this study. The Audits Committee waived the need for individual patient informed consent as this study is registered as a Clincal Audit project (register number CA720) and retrospective in nature. Patient confidentiality and data handling are in accordance with the Data Protection Act 1998 and General Medical Council guidelines.

\section{Results}

Between April 2015 and March 2016 (following establishment of OP MDT in April 2015), 120 patients had mastectomy, of whom $50(42 \%)$ underwent breast reconstruction with 78\% (39/50) choosing IBR (56\% implant reconstruction and 22\% autologous) (Tables 1 and 2). This is in contrast to the period between April 2014 and March 2015 preceding the OP MDM, when of 109 patients only 31 (28\%) had breast reconstruction with $64 \%$ (20/31) choosing IBR (45\% implant reconstruction and $19 \%$ autologous). The rate of DBR was lower, $22 \%(11 / 50)$, following introduction of the OP MDT versus 35\% (11/31) before OP MDM (Tables 1 and 2). Bilateral mastectomy was performed in 27 patients (11 implant reconstruction, four autologous, and 12 mastectomy alone). The increased rate of reconstruction was statistically significant at the $P<0.05$ level $(P=0.0144)$.

The mean time spent on discussion for patients in the OP MDM was 10 minutes compared to 2.5 minutes in the standard breast MDT.

Table I Mastectomy and reconstruction type

\begin{tabular}{|c|c|c|c|c|}
\hline \multirow[t]{3}{*}{ Operation type } & \multicolumn{2}{|l|}{ April 20I4-March 2015} & \multicolumn{2}{|l|}{ April 2015-March 2016} \\
\hline & \multicolumn{2}{|l|}{ Pre onco-plastic MDM } & \multicolumn{2}{|l|}{ Post onco-plastic MDM } \\
\hline & $\begin{array}{l}\text { Number of patients } \\
\text { (\% of total mastectomy) }\end{array}$ & $\begin{array}{l}\text { Mean age } \\
\text { (range) in years }\end{array}$ & $\begin{array}{l}\text { Number of patients } \\
\text { (\% of total mastectomy) }\end{array}$ & $\begin{array}{l}\text { Mean age (range) } \\
\text { in years }\end{array}$ \\
\hline Total mastectomy & 109 & $57(34-87)$ & 120 & $59(31-95)$ \\
\hline Mastectomy only & $78(7 \mid .5)$ & $63(34-87)$ & $70(58.3)$ & $67(37-95)$ \\
\hline Mastectomy/REC & $31(28.4)$ & $51.5(35-75)$ & $50(4 \mid .6)$ & $5 I .5(3|-7|)$ \\
\hline Implant IBR & $14(12.8)$ & $56(40-75)$ & $28(23.3)$ & $53(35-7 I)$ \\
\hline Autologous IBR & $6(5.5)$ & $48(39-54)$ & II (9.2) & $48(3 I-57)$ \\
\hline Total IBR & $20(18.3)$ & $52(39-75)$ & $39(32.5)$ & $50.5(3 I-7 I)$ \\
\hline Implant DBR & $2(1.8)$ & $49(47-5 I)$ & I (0.8) & $52 *$ \\
\hline Autologous DBR & $9(8.2)$ & $53(35-70)$ & $10(8.3)$ & $53(43-65)$ \\
\hline Total DBR & $11(10.1)$ & $51(35-70)$ & II (9.1) & $52.5(43-65)$ \\
\hline
\end{tabular}

Notes: $X^{2}=5.9825, P=0.0144$ (significant at $P<0.05$ level). *Only one patient in this group, mean age not used.

Abbreviations: DBR, delayed breast reconstruction; IBR, immediate breast reconstruction; MDM, multidisciplinary meeting; REC, reconstruction. 
Table 2 Reconstruction types and reconstruction rates

\begin{tabular}{|c|c|c|}
\hline Operation type & $\begin{array}{l}\text { Pre oncoplastic } \\
\text { MDM }\end{array}$ & $\begin{array}{l}\text { Post oncoplastic } \\
\text { MDM }\end{array}$ \\
\hline & $\begin{array}{l}\text { Reconstruction } \\
\text { rate } \% \text { total } \\
\text { reconstruction =31 } \\
\text { (number of patients) }\end{array}$ & $\begin{array}{l}\text { Reconstruction } \\
\text { rate \% total } \\
\text { reconstruction =50 } \\
\text { (number of patients) }\end{array}$ \\
\hline $\begin{array}{l}\text { Total reconstruction } \\
\text { rate }\end{array}$ & $28(31 / 109)$ & $41.6(50 / 120)$ \\
\hline Implant IBR & $45.1(14)$ & $56(28)$ \\
\hline Autologous IBR & $19.3(6)$ & $22(11)$ \\
\hline Total IBR & $64.5(20)$ & $78(39)$ \\
\hline Implant DBR & $6.2(2)$ & $2(1)$ \\
\hline Autologous DBR & $29(9)$ & $20(10)$ \\
\hline Total DBR & $35(\mathrm{II})$ & $22(11)$ \\
\hline
\end{tabular}

Abbreviations: DBR, delayed breast reconstruction; IBR, immediate breast reconstruction; MDM, multidisciplinary meeting.

\section{Discussion}

Our breast reconstruction rate $(42 \%)$ was twice the national average rate reported by NMBRA in 2009. Following the introduction of OP MDT our IBR has risen to $32.5 \%$ from $18 \%$. Implant-based reconstructions constituted $56 \%$ of all our IBRs with an autologous IBR of $22 \%$. These results are in line with recent analysis of National Trends in Immediate and Delayed Post-Mastectomy Reconstruction procedures in England. ${ }^{9}$ These showed that the annual number of reconstructions increased from 2182 in 2007 (14.9\% immediate reconstruction rate) to 3753 in 2013 (24.7\% immediate reconstruction rate). The dominant trend in procedure type was related to implant/expander-based reconstructions, which rose from $30 \%$ of all immediate reconstruction in 2007 to $54 \%$ in 2013 , and the use of free flap procedures increased marginally, the proportion rising from $17 \%$ to $21 \% .{ }^{9}$ There is still substantial regional variation in IBR rate across the English regions ranging from $13.1 \%$ to $36.7 \%{ }^{10}$

In our study, there was no significant difference in the cohort of mastectomy patients between 2015 and 2016 apart from the introduction of a dedicated OP MDM. We recognize that several complex factors are associated with uptake of breast reconstruction following mastectomy (age, ethnicity, income, education, tumor characteristics, healthrelated issues, surgeon/hospital factors, and psychological or other factors). ${ }^{4,11-16}$ We are also aware that other factors may have contributed to this increased rate of uptake, including an increased trend in breast reconstruction nationally ${ }^{9}$ and possible local logistical aspects (improved process in booking surgery, theater availability, and streamlined referral to plastic team); however, we believe that the introduction of the OP MDT was the key factor in this process and the comparative data in this study (Table 1) supports this assumption.
Due to the complexity of breast reconstruction surgery and the wide variety of options available, more specialist time is needed to deliver a tailored reconstruction service that meets patients' expectations. Recently, Cancer Research Campaign $\mathrm{UK}^{17}$ concluded that there is no enough time to discuss the more complex patient during MDTs. They found that over half of the MDT discussions were less than 2 minutes long, and because of the numbers discussed, meetings could last up to 5 hours. ${ }^{17} \mathrm{We}$ analyzed the timing of our MDTs. Our OP MDM discussion was an average of 10 minutes per patient discussed compared to 2.5 minutes to standard MDT. To make the best use of scarce specialist time, MDT discussions should focus more on difficult cases, and processes should be put in place to enable swifter decisions on patients going through standard treatment pathways. ${ }^{18}$

The current standard stipulates a maximum of 31 days from decision to treat to first treatment offered to breast cancer patients. ${ }^{19}$ We suggest that at the first week of their breast cancer diagnosis, patients who need mastectomy and are suitable for reconstruction are identified and triaged to the dedicated weekly OP MDM. Patients are seen by their breast surgeon with the BCNs for their initial results following the standard breast MDT where they are offered breast reconstruction information, options, and their initial preference explored. Preoperative photos are taken and shown in the OP MDM held the following week. In addition to oncoplastic surgeons and BCNs, plastic surgeons (with an expertise in microvascular breast reconstruction) constitute the core membership of this smaller, more specialized OP MDM. We run our weekly OP MDM immediately prior to our standard breast MDT and we allocate 10-15-minute discussion per patient compared to the standard breast MDT when patients are discussed in 2-3 minutes. OP MDM decisions are recorded electronically on $\mathrm{SCR}^{20}$ and a hard copy is filed into the patients' file so that these decisions can be shared between the wider standard MDT members. Following the OP MDM, patients are seen again with clear recommendations and offered the best options for their reconstruction according to their tumor biology and their own expectation. Prebooked appointments are available for patients to be seen by the plastic surgeon in the same week if they are considering autologous-type reconstruction. Dedicated combined operating theater lists are available for their immediate reconstructive surgery, thus avoiding any breach of the NHS 31-day target. OP MDM allows transparent decision making, standardization of care, and prospective recording of results. ${ }^{21}$

Our study is unique in providing an evidence-based improvement in breast reconstruction rate following the 
implementation of OP MDM intervention. This has led to offering more reconstructive options to our patients and streamlining their pathway with allocated current resources achieving their tailored reconstructive surgery within strict deadline targets. We recognize that the increased uptake of reconstruction seen in our study might be coincidental, and that causality, although inferred, is unproven.

\section{Conclusion}

Our study has shown the positive impact of OP MDM in achieving a breast reconstruction rate of $42 \%$ (twice as the national average rate). Seventy-eight percent of women chose to have immediate-type reconstruction following their mastectomy, with $56 \%$ being implant-based reconstruction and $22 \%$ autologous-type reconstruction. We recommend that all units providing breast reconstruction should establish a standalone OP MDM to facilitate best patient care.

\section{Acknowledgments}

This study has been accepted as a poster presentation at the Association of Breast Surgery ABS Annual Conference, 15-16th May, 2017, Belfast, UK.

We wish to thank our Audit and IT department for their help in data collection with special thanks to our OP MDM Co-ordinator Julie Booth for her assistance in retrieval of reconstruction data from SCR.

\section{Disclosure}

The authors report no conflicts of interest in this work.

\section{References}

1. National Institute for Health and Clinical Excellence (NICE). Early and locally advanced breast cancer: diagnosis and treatment. (Clinical guideline 80) London: NICE, 2009. Available from: http://www.nice. org.uk/nicemedia/pdf/ CG80NICEGuideline.pdf. Accessed January 5, 2017.

2. Jeevan R, Cromwell D, Browne J, et al. Second Annual Report of the National Mastectomy and Breast Reconstruction Audit 2009. Leeds: The NHS Information Centre, 2009. Available from: http://www.ic.nhs. uk/mbr. Accessed January 7, 2017.

3. Jeevan R, Cromwell D, Browne J. et al. Third Annual Report of the National Mastectomy and Breast Reconstruction Audit 2009. Leeds: The NHS Information Centre, 2010. Available from: http://www.ic.nhs. uk/mbr. Accessed January 7, 2017.

Breast Cancer - Targets and Therapy

\section{Publish your work in this journal}

Breast Cancer - Targets and Therapy is an international, peerreviewed open access journal focusing on breast cancer research, identification of therapeutic targets and the optimal use of preventative and integrated treatment interventions to achieve improved outcomes, enhanced survival and quality of life for the cancer patient.
4. Brennan ME, Spillane AJ. Uptake and predictors of post-mastectomy reconstruction in women with breast malignancy - systematic review. Eur J Surg Oncol. 2013;39(6):527-541.

5. Houssmi N, Sainsbury R. Breast cancer: multidisciplinary care and clinical outcomes. Eur J Cancer. 2006;42(15):2480-2491.

6. Kesson EM, Allardice GM, George WD, Burns HJG, Morrison DS. Effects of multidisciplinary team working on breast cancer survival: retrospective, comparative, interventional cohort study of 13,722 women. BMJ. 2012;344:e2718.

7. Taylor C, Shewbridge A, Harris J, Green JS. Benefits of multidisciplinary teamwork in the management of breast cancer. Breast Cancer (Dove Med Press). 2013;5:79-85.

8. Association of Breast Surgery, British Association of Plastic Reconstructive and Aesthetic Surgeons. Oncoplastic breast reconstruction: guidelines for best practice 2012. Available from: http://www.associationofbreastsurgery.org.uk/media/23851/final_oncoplastic_guidelines_for_use.pdf. Accessed January, 212017.

9. Mennie JC, Mohanna PN, O’Donoghue JM, Rainsbury RM, Cromwell DA. National trends in immediate and delayed post-mastectomy reconstruction procedures in England: a seven-year population-based cohort study. EJSO. 2017;43(1):52-61.

10. Jeevan R, Mennie JC, Mohanna PN, O’Donoghue JM, Rainsbury RM, Cromwell DA. National trends and regional variation in immediate breast reconstruction rates. Br J Surg. 2016;103(9):1147-1156.

11. Howard-McNatt MM. Patients opting for breast reconstruction following mastectomy: an analysis of uptake rates and benefit. Breast Cancer (Dove Med Press). 2013;5:9-15.

12. Ogrodnik A, MacLennan S, Weaver D, James T. Barriers to completing delayed breast reconstruction following mastectomy: a critical need for patient and clinician education. J Cancer Educ. 2016.

13. Bellavance EC, Kesmodel SB. Decision-making in the surgical treatment of breast cancer: factors influencing women's choices for mastectomy and breast conserving surgery. Front Oncol. 2016;29;6:74.

14. Oh DD, Flitcroft K, Brennan ME, Spillane AJ. Patterns and outcomes of breast reconstruction in older women - a systematic review of the literature. Eur J Surg Oncol. 2016;42(5):604-615.

15. Wong A, Snook K, Brennan M. et al. Increasing breast reconstruction rates by offering more women a choice. ANZJ Surg. 2014;84(1-2):31-36.

16. Lam TC, Winch CJ. What would women choose when given a choice in breast reconstruction? Plast Reconstr Surg Glob Open. 2016;4(9):e1062.

17. Cancer Research UK. Meeting patients' needs: improving the effectiveness of multidisciplinary team meetings in cancer services. Available from: http://www.cancerresearchuk.org/mdts-research. Accessed January $21,2017$.

18. Independent Cancer Taskforce. 2015. Achieving World-Class Cancer Outcomes: A Strategy for England 2015-2020. London: Independent Cancer Taskforc Available from: http://bit.ly/1Idwf5W. Accessed January 2017.

19. NHS Cncer Plan(2002). Available from: http://www.dh.gov.uk/en/ Publicationsandstatistics/PublicationsPolicyAndGuidance/DH4009609. Accessed January 21, 2017.

20. Somerset Cancer Rgiste. Available from: http://www.somersetscr.nhs. uk. Accessed January 21, 2017.

21. Rusby JE, Gough J, Harris PA, MacNeill FA. Oncoplastic multidisciplinary meetings: a necessity or luxury? Ann R Coll Surg Engl. 2011;93(4):273-274.
The manuscript management system is completely online and includes a very quick and fair peer-review system, which is all easy to use. Visit http://www.dovepress.com/testimonials.php to read real quotes from published authors. 